\title{
Self-Supported NHC-Palladium Catalyst for the Strecker Synthesis
}
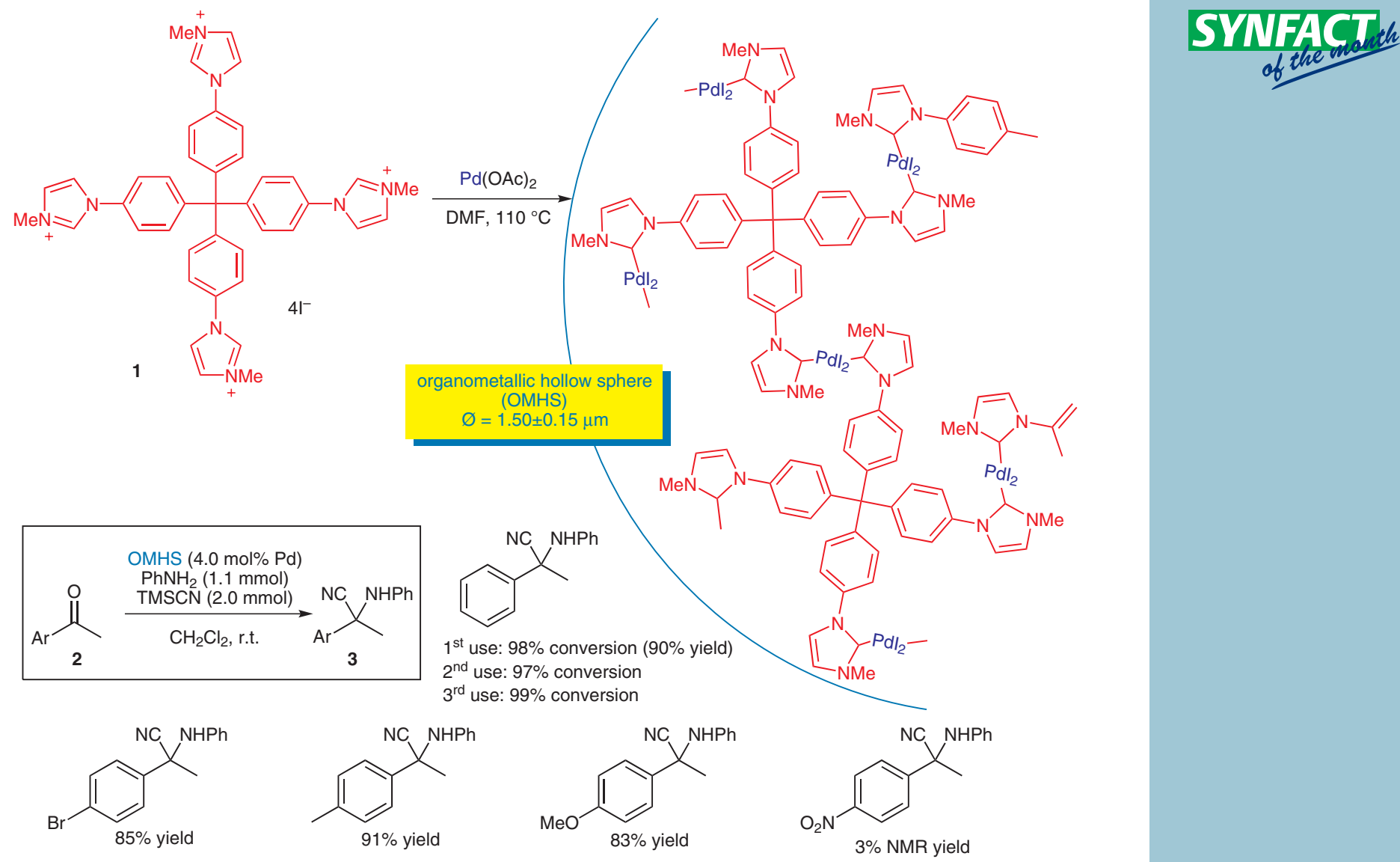

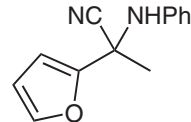

$89 \%$ yield

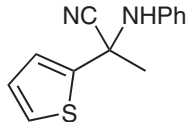

$44 \%$ yield<smiles>CC(C#N)(c1ccccc1)c1cccnc1</smiles>

$50 \%$ yield<smiles>CC(N)(c1ccccc1)c1cccc2ccccc12</smiles>

$65 \%$ yield

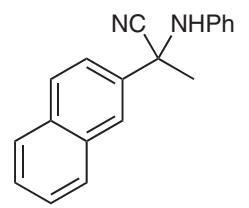

$86 \%$ yield

Polymer-Supported Synthesis

Key words

organometallic hollow spheres

Strecker reaction

ketones

palladium

Significance: The organometallic hollow sphere (OMHS) catalyst was prepared by self-supporting of $\mathrm{Pd}(\mathrm{OAc})_{2}$ and tetrahedral $\mathbf{1}$ having four imidazolium salts. The Strecker reaction of aryl methyl ketones 2 with OMHS gave the corresponding $\alpha$-aminonitriles 3 in 3-91\% yield.
Comment: The average diameter of OMHS was $1.50 \pm 0.15 \mu \mathrm{m}$. OMHS was reused twice without loss of catalytic activity. The catalyst was characterized with SEM, TEM, EDS, TGA, elementary analysis, and solid-phase ${ }^{13} \mathrm{C}$ NMR spectroscopy.

SYNFACTS Contributors: Yasuhiro Uozumi, Yoichi M. A. Yamada

DoI: 10.1055/s-0030-1259462; Reg-No.: Y00711SF 